\title{
A Ditadura que se Perpetua: Direitos Humanos e a Militarização da Questão Social
}

\author{
Ana Vládia Holanda Cruz \\ Faculdade DeVry Fanor, CE, Brasil. \\ Adriana Eiko Matsumoto \\ Universidade Federal Fluminense, RJ, Brasil.
}

\author{
Tatiana Minchoni \\ Universidade Federal de Santa Catarina, SC, Brasil. \\ Soraya Souza de Andrade \\ Universidade Federal do Pará, PA, Brasil.
}

Resumo: O presente artigo contempla um estudo teórico sobre os processos de permanência e de alastramento no corpo social, no tocante às políticas de segurança, dos elementos que se forjaram na história longa de nosso território brasileiro, desde a época da invasão colonial, dando ênfase ao acirramento de suas contradições na ditadura empresarial-militar e à contradição posta entre a militarização da questão social e a luta pela garantia dos direitos humanos na atualidade. A partir das reflexões da criminologia crítica ou radical e da análise do papel das ciências numa perspectiva materialista-histórico e dialética, buscou-se evidenciar os processos de construção da figura do inimigo interno hoje qualificado como "delinquente", bem como os desdobramentos da constituição de processos de criminalização em determinados modos de sociabilidade e de subjetividades. Nesse sentido, compreende-se que à Psicologia, como ciência e profissão, cabe a tarefa de posicionar-se frente às expressões da desigualdade social buscando desvelar as determinações históricas e a relação com a totalidade da qual emergem tais contextos.

Palavras-chave: Ditadura, Direitos Humanos, Militarização da Questão Social.

\section{The Dictatorship that Remains: Human Rights and the Militarization of the Social Issue}

\begin{abstract}
The present article is a theoretical study about the permanence and spread processes in the social body, regarding the security policies, of the elements that were forged in the long history of our Brazilian territory, from the time of the colonial invasion, emphasizing the contradictions in the military-business dictatorship, and the contradiction between the militarization of the social question and the struggle for the guarantee of human rights today. From the reflections of critical or radical criminology and the analysis of the role of sciences in a materialist-historical and dialectical perspective, this study sought to highlight the processes of construction of the figure of the internal enemy today qualified as "delinquent", as well as the unfolding of the constitution of processes of criminalization in certain modes of sociability and subjectivities. In this sense, it is understood that psychology, as a science and profession, has the task of positioning itself before the expressions of social inequality, seeking to unveil the historical determinations and the relation with the totality from which emerge such contexts.
\end{abstract}

Keywords: Dictatorship, Human Rights, Militarization of the Social Issue. 


\title{
La Dictadura que se Perpetúa: Derechos Humanos y la Militarización de la Cuestión Social
}

\begin{abstract}
Resumen: El presente artículo contempla un estudio teórico sobre los procesos de permanencia y de extensión en el cuerpo social, en lo que se refiere a las políticas de seguridad, de los elementos que se forjaron en la larga historia de nuestro territorio brasileño, desde la época de la invasión colonial, dando énfasis al crecimiento de sus contradicciones en la dictadura empresarial-militar, y la contradicción entre la militarización de la cuestión social y la lucha por la garantía de los derechos humanos en la actualidad. A partir de las reflexiones de la criminología crítica o radical y del análisis del papel de las ciencias bajo una mirada materialista-histórica y dialéctica, se buscó evidenciar los procesos de construcción de la figura del enemigo interno hoy calificado como "delincuente", así como los desdoblamientos de la constitución de procesos de criminalización en determinados modos de sociabilidad y de subjetividades. En ese sentido, se comprende que a la psicología, como ciencia y profesión, cabe la tarea de posicionarse frente a las expresiones de la desigualdad social buscando desvelar las determinaciones históricas y la relación con la totalidad de la cual emergen tales contextos.
\end{abstract}

Palabras clave: Dictadura, Derechos Humanos, Militarización de la Cuestión Social.

Os que trabalham têm medo de perder o trabalho.

Os que não trabalham têm medo de nunca encontrar trabalho.

Quem não tem medo da fome, tem medo da comida.

Os motoristas têm medo de caminhar e os pedestres têm medo de ser atropelados.

A democracia tem medo de lembrar e a linguagem tem medo de dizer. Os civis têm medo dos militares, os militares têm medo da falta de armas, as armas têm medo da falta de guerras.

Eduardo Galeano (1940/2013, p. 83)

E há quem tenha medo que o medo acabe. Mia Couto ${ }^{1}$

A vida de um adolescente negro, no Brasil atual, encarna séculos de História. Sua vida se constitui, em pleno século XXI, a partir de uma formação social hierárquica e mantenedora de privilégios, fundada na concentração de poder e riquezas pela força. Traz as marcas do escravismo, da clandestinidade da cultura (d)e resistência e da repressão; da eugenia e do higie- nismo, como políticas reproduzidas em larga escala; do racismo autoproclamado científico com o acolhimento de Lombroso e Ferri em terreno tropical; da abordagem manicomial e das políticas de controle e hiperencarceramento.

A República, em sua democracia de baixíssima intensidade, não foi capaz de oferecer-lhe senão um lugar social subalternizado e uma inclusão perversa, limitada ao que é mais adequado e necessário a mais eficiente reprodução do capital e do funcionamento da ordem política em favor dos que dominam (Martins, 1997). Ele ocupa, de forma precária, as funções de menor renda e status no mundo do trabalho, mora em ocupações arriscadas e afastadas pela gentrificação; tem menos acesso à educação e à saúde; pouca representação na política institucional e morre mais cedo.

Sua trajetória também pode ser contada por meio das manifestações históricas das instituições privativas de liberdade. Desde o contexto fundacional do Brasil com a invasão estrangeira, os "moinhos de gastar gente" (Ribeiro, 1995) se alteraram como consequência das opções político-econômicas das elites. As técnicas de tortura se modificaram: dos açoites aos choques, do pau de arara ao asfixiamento com sacos plásticos, mas a prática continua. A história dos atuais Centros Educacionais - em um contexto no qual

${ }^{1}$ Despertai Consciência (Difusor). (2013). Murar o Medo - Fala de Mia Couto na Conferência de Estoril de 2011. Recuperado de https:// www.youtube.com/watch?v=5xtgUxggt_4 
o aparato legal da Proteção Integral não foi capaz de modificar arraigadas concepções menoristas - é a mesma da Fundação Estadual para o Bem-estar do Menor (Febem), do Serviço de Assistência ao Menor (SAM), das Casas de Correção e dos Calabouços: é a história do encarceramento no Brasil, com os mesmos corpos enclausurados - jovens, negros, pouco ou nada escolarizados e ocupando com instabilidade as mais baixas posições no mundo do trabalho, para o qual têm obrigação de entrar muito cedo. "Mudou a letra da lei porém não o espírito da coisa. (...) Em suma: [são os] punidos e mal pagos" (Batista, 1990, p. 36), os mesmos a ganharem o estigma mais letal já produzido: o de "delinquentes".

Essa é uma das facetas mais cruéis da materialização de um direito - e de todo o aparato que o acompanha - desigual, no qual uns são tidos como descartáveis ou, para colocar de forma mais explícita, "matáveis", e outros como sujeitos dotados de plenas garantias e foro privilegiado. Para uns a prática secular do vigilantismo, da repressão e do controle penal; para outros a leniência com as infrações e a proteção que estimula o elitismo intolerante.

Tal divisão não se restringe ao mundo do trabalho ou ao acesso à justiça e aos mecanismos formais e informais de punição. Ela é notória na divisão espacial das cidades e na intensificação de sua guetização. As ocupações militares, colocando populações e territórios inteiros sob gestão policial, tem provocado inúmeras mortes e acirrado debates com pouco diálogo institucional. As perguntas permanecem ("Onde está Amarildo?”, “Porque o senhor atirou em mim?”) e a resposta muitas vezes tem sido a presença militar a controlar enterros para evitar que comoções virem revolta massiva.

Assim, sem compreendermos que a relação entre o hoje e o ontem é eminentemente dialética e de permanências, não conseguiremos operar rupturas significativas no presente. Em tempos de "pós-verdade", vale ressaltar que o fio de sua ligação se encontra na luta de classes - classes de carne e osso, que possuem gênero, raça/etnia, geração, orientação sexual.

Walter Benjamin, nas suas teses Sobre o Conceito de História, apresenta a ideia de que só à humanidade redimida cabe o passado em sua inteireza. Isso significa que, sem a rememoração e a reparação, a emancipação não é possível e sequer os mortos estarão seguros. Profana-se sua luta, distorce-se sua causa e banaliza-se a sua permanência. Esta leitura nos coloca a tarefa de "escovar a história a contrapelo", uma vez que, deixado à própria sorte, o capitalismo apenas intensificará opressões e explorações, acossando os direitos humanos até a sua desfiguração. A ordem pós-1989, lembra Douzinas (2011), combina com maior intensidade um sistema econômico que gera enormes desigualdades estruturais com uma ideologia jurídico-política que promete dignidade e equidade.

Ao percebemos historicamente a realidade entendemos, portanto, que a segurança, erigida como prioridade política para a manutenção da ordem, mudou constantemente seu pretexto no decorrer do tempo (a insurreição, a subversão, a proteção da propriedade, a "ameaça comunista", o terrorismo, o vandalismo etc.), sem nunca alterar o seu propósito: governar as populações (Agamben, 2014). Em seu nome, uma carta branca é dada para a suspensão de direitos e de liberdades individuais e coletivas, inscrevendo o Estado no paradigma da Exceção - não como forma de lidar com problemas e ameaças pontuais dentro de um determinado período, mas, ao contrário, como técnica permanente de governo (Agamben, 2004).

"Articular o passado historicamente significa apoderar-se de uma lembrança tal como ela lampeja num instante de perigo", afirma a sexta tese de Benjamin (Löwy, 2005). É esta a faísca que nos move na escrita deste artigo. A atualidade de uma rarefeita democracia reflete nossa trajetória político-econômica, concentradora de poder e riquezas, e é mantida por um aparato repressivo que se intensifica, mais recentemente, pela militarização da "questão social", evidenciando a típica produção de precarização de condições de vida imposta pelo modo de produção capitalista à classe trabalhadora. Portanto, cabe também a nós, psicólogas(os), a tarefa de recuperar o indivíduo na intersecção de sua história com a história de sua sociedade (Lane, 1984), reescrevendo a trajetória coletiva pela recusa em se juntar ao cortejo do falso progresso democrático.

\section{O estado de Exceção permanente e a militarização da "questão social"}

A política criminal, como parte estruturante da lei e da ordem na sociabilidade do capital, é uma chave fundamental para a interpretação dos conflitos de classe e raça no Brasil. Por política criminal entende-se o conjunto de princípios e recomendações para a reforma ou a manutenção da legislação penal e dos 
órgãos encarregados de sua aplicação (Batista, 2011), sendo os sistemas judiciário, de segurança pública e penitenciário seus principais elementos constitutivos. Dentre os conhecimentos que mais influenciaram tais modificações, a criminologia, sobretudo em sua versão tradicional positivista, merece destaque por cumprir um importante papel de redefinição dos "criminosos", dos crimes e das penas, alterando a legislação e os objetivos institucionais do aparelho penal e legitimando a ordem política e econômica estabelecida. Olhemos, portanto, mais detalhadamente sobre cada um dos sistemas componentes da Política Criminal e seus desdobramentos para a democracia no Brasil.

O sistema judiciário, sobre o qual, desde Cesare Beccaria e sua obra Dos Delitos e das Penas (1764/2006), recai a concepção de neutralidade, precisa antes de tudo ser desmistificado. Em geral, a história do direito é apresentada de forma quase autônoma e descolada com respeito ao contexto histórico de suas formulações e aos interesses econômicos e políticos que fundamentam a criação das normas.

Segundo o professor Nilo Batista (2011), a missão do direito, na perspectiva adotada hegemonicamente, seria identificada com a própria garantia das condições de vida em sociedade, tendo como finalidade a defesa e a preservação dos interesses do corpo social. No caso do direito penal, refletido em ampla medida na justiça juvenil, seu intento seria a proteção legítima e eficaz dos bens jurídicos fundamentais do indivíduo e da coletividade. Mas deve-se perguntar: o que significarão os "interesses do corpo social" em uma sociedade de classes, na qual os interesses em jogo são estruturalmente antagônicos? Se o crime é um constructo social e não um ente natural ou ontológico, "aparecido na natureza como os peixes, os abacates e as esmeraldas", como provoca Vera M. Batista (2012), quais são os determinantes para a sua definição e, sobretudo, para a seleção dentre o imenso quadro da "criminalidade" daqueles que devem ser registrados, apurados, julgados e, por fim, punidos?

O direito é, portanto, político, assim como a definição de crime e de "criminoso". Damos três exemplos reveladores sobre a opção política das leis: a criminalização do aborto, permitido na França e nos Estados Unidos, por exemplo, desde a década de 1970 (tutela sobre direitos sexuais e reprodutivos, a partir de determinada moral); a abordagem penal sobre a produção, o consumo e o comércio de algumas drogas (interesses econômicos); e a frouxa legislação ambiental, privilegiando os interesses do agronegócio em detrimento da preservação dos ecossistemas (contradição bens tutelados versus interesses comuns).

Os aparentes objetivos do direito penal, expressos através da formulação de proteção dos "interesses", "necessidades", "valores" ou "bens jurídicos" essenciais para a existência da vida em sociedade, possuem certos pressupostos ideológicos para sua aceitação, como as noções de unidade social (e não de divisão), de identidade de classes (e não de contradição), de igualdade entre os componentes do corpo social (e não de desigualdades reais, inclusive no seu acesso à justiça) e de liberdade individual (e não de exploração e opressão) (Batista, 2011). Neste estudo defende-se que, em uma sociedade de classes, o sistema criminal protege prioritariamente relações sociais, interesses e valores da classe dominante, ainda que aparente universalidade.

É do campo da Criminologia Crítica ou Radical que partem as análises mais contundentes sobre o funcionamento seletivo do sistema de justiça e da política criminal. Em sua vertente positivista tradicional, nascida na segunda metade do século XIX, a criminologia reforçou a idealização de um saber jurídico neutro, puramente técnico (para não dizer científico) e alheio às tensões da realidade social, limitando-se ao exame causal-explicativo do crime e de seus autores. Embora a Escola Positivista tenha sofrido diversas modificações e acumulado críticas relacionadas, sobretudo, ao determinismo de suas proposições, seu modelo permanece ativo nas diversas instâncias da política, de modo que mesmo a produção jurídica continua furtando-se ao exame de sua própria legitimidade, dos determinantes de sua formulação conceitual e do desempenho concreto das agências encarregadas de sua aplicação. No Brasil, mais do que uma escola de pensamento, o positivismo criminológico constituiu-se como uma cultura que sofreu continuamente atualizações e sofisticações em seus esquemas classificatórios e hierarquizantes - a Psicologia lhe sabe bem - e que continua sendo apropriado pelo campo jurídico e pelo senso comum, por exemplo, na noção de "má índole" ou de "índole criminosa", indicando a percepção de que alguém possa ter uma propensão natural ao crime. Tal como afirma Vera M. Batista (2012),

O positivismo não foi apenas uma maneira de pensar, profundamente enraizada na intelligentsia e nas práticas sociais e políticas 
brasileiras; ele foi principalmente uma maneira de sentir o povo, sempre inferiorizado, patologizado, discriminado e, por fim, criminalizado. Funcionou, e funciona, como grande catalisador da violência e da desigualdade características do processo de incorporação da nossa margem ao capitalismo central (Batista, 2012, p. 48).

Assim, sem questionar a construção política do direito - "como, por que e para que se ameaçam penalmente determinadas condutas e não outras, que atingem determinados interesses e não outros, com o resultado prático de atingir quase exclusivamente pessoas de determinada classe e não de outra" -, ao conceber os "comportamentos desviantes" a partir de um prisma individualizante e ao naturalizar as funções sociais desempenhadas pela pena, a criminologia positivista cumpriu um importante papel político de conservação e legitimação da ordem estabelecida (Batista, 2011, p. 29). Por legitimação, com base na criminóloga venezuelana Lola Aniyar de Castro, entendemos "toda forma de convalidar, autorizando, principalmente através da promoção do consenso social, um determinado sistema de dominação" (Castro, 2005, p. 43). Por seu turno, a função conservadora ou de controle social corresponde à produção e utilização de conhecimentos, táticas e estratégias para a construção da hegemonia e, em sua ameaça, para a submissão forçada daqueles que não se integram à ideologia dominante.

Essa função legitimadora, historicamente, começa a ganhar um corpo teórico coeso e de peso com a Escola Liberal Clássica sobre o crime, o direito e a pena, ressaltada por muitos apenas por seu aspecto filosófico, "humanista" e limitador do direito punitivo em face dos excessos do Ancien Regime. Embora correta, tal caracterização é insuficiente com relação à formulação e, sobretudo, às aplicações e utilidades da teoria Iluminista incorporada aos sistemas jurídico-penais. Ademais, ela deixa oculta a noção de tempo forjada na concepção burguesa de sociabilidade que acompanhou a ideologia do trabalho, tornando possível o princípio fundamental de proporcionalidade da pena, conforme proposto por Beccaria, e a própria instituição da Prisão - forma especificamente burguesa de punição, na passagem ao capitalismo.

Se a pena não consiste em mera consequência do delito, mas compõe um sistema punitivo concreto com práticas penais específicas que variam de acordo com o momento histórico, olhar para seu desenvolvimento pode nos auxiliar a compreender as variações da política criminal, uma vez que esta mesma não se concretiza tendo em vista apenas a melhor forma de combater o crime e a violência. $O$ uso e a rejeição de certas punições, assim como a origem e a intensidade dos sistemas punitivos - nos ensinam Rusche e Kirchheimer (2004), Foucault (1987) e Melossi e Pavarini (2006) em seus diferentes enfoques -, são determinados por forças sociais que correspondem a um dado estágio de desenvolvimento econômico: todo sistema de produção tende a descobrir formas punitivas que correspondem ao estágio de suas forças produtivas, resumem os autores.

Do mesmo modo, o aspecto institucional - assim como seu funcionamento, seja ele oficial ou não - da reação ao comportamento desviante e do correspondente controle social não deve ser considerado como menos relevante em relação à formação de um sistema penal dado. É ele elemento fundamental da própria sociologia jurídico-penal, consistindo em sua materialização na vida social e cotidiana, ou seja, na forma como atinge a vida concreta de sua clientela preferencial (Castro, 2005). Efetivamente, apenas analisando esta unidade pode-se alcançar a função prática do direito (Baratta, 2002).

No terreno da segurança, a superlotação dos presídios e o crescimento de mortes por ações policiais no campo e na cidade são manifestações do mesmo fenômeno: a militarização da "questão social". Conforme já salientou Netto (2012), “[...] a articulação orgânica de repressão às "classes perigosas" e assistencialização minimalista das políticas sociais dirigidas ao enfrentamento da 'questão social' constitui uma face contemporânea da barbárie” (p. 429).

Compreendemos, assim, a "questão social" como um conceito que expressa na aparência as condições de pauperismo a que está submetida a classe trabalhadora a partir das condições concretas da exploração da força de trabalho, as quais vão se modificando no fio da história (Netto, 2001). Trata-se, pois, de um processo de naturalização que torna a "questão social" traço a priori da realidade social, tornando-se alvo de intervenções que visam minimizar seus efeitos, a partir de uma ação tutelada do Estado para com a população tomada como em situação de vulnerabilidade. Nesse sentido, nos afastamos das concepções eivadas de ideologias reformistas e conservadoras, que visam dissertar sobre a manifestação fenomênica da produ- 
ção de desigualdades, reproduzindo multiplicidades (questões de segurança, de violência, de "criminalidade", entre outros) como elementos isolados e com especificidades próprias, sem qualquer relação com a totalidade de onde emergiram.

Multifacetada, a militarização da "questão social" também se expressa no "caveirão" que tudo arrasta na Maré; na abordagem criminalizante de jovens negros/as; no aumento de tiroteios em áreas com Unidades de Polícia Pacificadora (UPP) na ordem de 13.746\%, passando de 13 em 2011 para 1.555 em 2016; no canto de guerra da Polícia Militar (PM) do Paraná (Eu miro na cabeça, atiro sem errar / Se munição eu já não tiver, pancadaria vai rolar / Bate na cara, espanca até matar / Arranca a cabeça e explode ela no ar / Arranca a pele e esmaga os seus ossos / Joga ele na vala e reza um Pai Nosso); na Chacina de Messejana, com 11 mortos, em Fortaleza; na condenação de Rafael Braga; na perseguição a Mirian França; no Velório sem corpo de Amarildo; na política higienista e manicomial da Cracolândia, em São Paulo.

Eis o Estado-Centauro (Wacquant, 2001), guiado por uma cabeça (neo)liberal e um corpo autoritário, que destitui direitos e aplica a doutrina do laissez-faire em relação às desigualdades sociais e aos mecanismos que as geram, mas mostra-se brutalmente punitivo quando se trata de administrar suas consequências no nível cotidiano. Essa violência inscreve-se em uma tradição multissecular de controle pela força, tradição oriunda do colonialismo, fortalecida por conflitos agrários e por duas décadas de ditadura empresarial-militar. Mais recentemente, ganha força no trampolim político da bancada da bala em programas policialescos, na reedição das medidas de Tolerância Zero, apresentadas como inovação em um verdadeiro Museu das Grandes Novidades, e com a pressão de ruralistas e do agronegócio.

Retornando ao autor francês, para Wacquant (2003), o Estado keynesiano, cuja missão seria contrapor-se aos ciclos recessivos da economia de mercado, proteger as populações mais vulneráveis e reduzir as desigualdades mais gritantes do modo de produção e da sociabilidade capitalista, foi sucedido por um Estado que se pode chamar de neo-darwinista, que se baseia na competição, celebra a responsabilidade individual irrestrita e tem como contrapartida a irresponsabilidade coletiva e, deste modo, política.

Conclusão semelhante chega o teórico Agamben (2014) ao destacar a conexão entre a crescente mul- tiplicação dos mecanismos de segurança (inclui-se, aí, as balas de borracha, bombas de gás lacrimogêneo etc.) e as reduzidas possibilidades de participação política, a ponto de devermos nos perguntar se vivemos em sociedades que ainda podem ser qualificadas de democráticas ou se reduzimos nossa participação política a um estatuto jurídico, burocratizado, que praticamente se limita à potência pífia de um voto.

Vale ressaltar que o militarismo constitui um vasto conjunto de hábitos, interesses, ações e pensamentos associados com o uso de armas e com a guerra, mas que transcende aos objetivos puramente militares (Bobbio, 1998). O militarismo também não se restringe ao estatuto de determinada polícia ou ao espelhamento institucional do exército, mas é um fenômeno que se espraia por toda a sociedade.

No Brasil, antes do regime ditatorial, as PMs encerravam um papel secundário no trato das questões de segurança interna. Embora já existisse a atual separação entre as Polícias Civil e Militar, foi sobretudo a partir de 1969, portanto no auge da repressão política, que houve uma reversão nas funções das corporações, de modo que as polícias militares saíram de seu aquartelamento e foram lançadas nas ruas com o objetivo de fazer o papel do policiamento ostensivo e de manutenção da ordem pública (Zaverucha, 2010). O treinamento e a atuação das PMs, no entanto, não está focado na garantia de direitos. Muito pelo contrário, a cultura institucional é guiada por uma lógica de guerra que transforma as ruas em campos de batalha, criminaliza a condição de pobreza e os movimentos sociais e transforma questões de saúde, como o consumo e a dependência de drogas, em declarada Guerra.

A chamada Constituição Cidadã manteve a estrutura de militarização da segurança - ou seja, de adoção e uso de modelos, conceitos, doutrinas e procedimentos militares em atividades de natureza civil (Cerqueira, 1998) - além de garantir a supremacia em número de homens e poder de fogo (igualmente alcançada durante o período autocrático burguês) da Polícia Militar sobre a Polícia Civil.

Nesse sentido, o processo de desmilitarização das polícias - bandeira popular que ganhou maior fôlego desde as chamadas "Jornadas de Junho", em 2013 passa, inicial e essencialmente, por um corajoso enfrentamento das heranças da ditadura, presentes inclusive em termos legais - tarefa nada fácil, vide as amplas e sintomáticas dificuldades na constituição e atuação de uma efetiva Comissão da Verdade. Ademais, os legados 
do autoritarismo nas instituições policiais e nas políticas de segurança precisam ser encarados não somente na esfera prática (através da expansão dos mecanismos de controle e participação social, elaboração de uma nova abordagem que reconheça a diversidade do fenômeno da violência e não criminalize a situação de destituição, revitalização dos espaços públicos ao revés da ameaça ostensiva e do domínio territorial etc.) mas, igualmente, nos campos cultural e simbólico. Até hoje, para citar apenas um exemplo, a polícia militar de São Paulo presta homenagem aos golpes militares do Estado Novo e de 1964 em seu brasão de armas, além das repressões ao levante de 1935 e à greve dos operários de 1917, dentre outras ocorrências de contenção a manifestações populares.

A atuação excessivamente violenta das PMs guarda íntima relação com a formação dos policiais e a composição interna da instituição, e também deve ser incorporada a esse debate. Fincada nos valores da disciplina e da hierarquia, a estrutura organizacional militarizada não permite aos que nela ingressam o mínimo questionamento sobre suas funções e responsabilidades. Ordens não podem ser discutidas e tradições, por vezes com fortes matizes genocidas e preconceituosas ao ponto de incitar pública e impunemente os crimes de tortura e homicídio, tendem a ser perpetuadas. As queixas sobre as condições de trabalho e os dilemas éticos que porventura seus operadores enfrentem, como poderia ser o caso diante dos protestos e reivindicações populares - "Manter a ordem pode ser uma missão eticamente sustentável se a ordem real está alicerçada em uma injustiça flagrante?" (Rolim, 2006) -, são silenciados pela obrigação da submissão e o despotismo dos oficiais.

Em qualquer outro contexto laboral, a forma como se concretizam cotidianamente tais princípios seria caracterizada como assédio moral. No entanto, o autoritarismo presente nas organizações militares aumenta sensivelmente as possibilidades de adoecimento dos policiais e propicia a reprodução da violência (banalizada em sua própria formação) junto à população que deveria proteger.

Mantida por meio de privilégios e punições que compreendem a simbologia e a prática da humilhação, a disciplina militar doutrina ao longo dos anos que é possível "corrigir" sujeitos através do castigo e do sujeitamento forçado à autoridade - algo extremamente perigoso de ser reproduzido pelos detentores do "uso legítimo da força" quando tratados, eles mes- mos, por meio da brutalidade e do exercício bélico. Não menos importante é a consideração do sofrimento psíquico a que está sujeito o próprio profissional da segurança pública, pressionado a dar respostas imediatas a um problema estrutural e difícil de ser efetivamente enfrentado nos marcos de uma sociedade produtora de desigualdades.

O outro front invisível da guerra está no campo. Sequências de chacinas foram realizadas, sobretudo no Norte e Centro-oeste do Brasil, contra campesinos(as) e indígenas que lutam por reforma agrária e demarcação de terras para os povos originários. A mais recente ocorreu em de 24 de maio de 2017: nove homens e uma mulher ligados à Liga dos Camponeses Pobres (LCP) foram mortos na fazenda Santa Lúcia, localizada no município de Pau d'Arco, sudeste do Pará, durante ação das Polícias Civil e Militar. Outras 14 pessoas foram baleadas e ficaram feridas. É o maior morticínio, em uma única investida, desde Eldorado dos Carajás.

De 2007 para cá, os assassinatos motivados por disputas de terras mais que dobraram, segundo dados da Comissão Pastoral da Terra (CPT). O Brasil, considerado um dos países mais perigosos do mundo para ambientalistas, teve 58 assassinatos registrados pela CPT em 2016 - um crescimento de $23 \%$ com relação aos casos registrados em 2015. Neste ano, já foram contabilizadas 36 mortes por conflitos agrários.

A construção da figura do inimigo delinquente um Outro diferenciado de nós e de quem precisamos, a qualquer custo, nos proteger - foi forjada há séculos e ainda permanece como um assustador consenso social. Ela foi primeiramente legitimada enquanto uma ideia, apresentada como necessidade e sustentada por teorias dentro de uma concepção moderna de Estado que amparou dominações e práticas autoritárias com vernizes democráticos. Virou política pública, algumas vezes expressa (lei antiterror) outras veladas ("guerra às drogas", objeto inanimado que leva o "caveirão" e a gestão militar para as favelas), mas apresentando-se, invariavelmente, como preservação social. O massacre multissecular, portanto, foi e é feito "em nome da segurança", da "Defesa Social".

O trabalho ideológico foi bem-feito: ainda hoje, "bandidos" e "vagabundos" - independentemente de sua idade - não merecem direitos, pois não são concebidos como humanos iguais. São vidas indignas de serem vividas, pelo menos em sociedade. São seres humanos privados do caráter de pessoas por um 
direito penal subterrâneo (Zaffaroni, 2007) que comemora sua morte em massa. Cada corpo no chão é "um a menos" numa sociedade que aprova amplamente a pena de morte e a prisão perpétua': "vagabundo não merece perdão".

A maioria legitima o que, em tempos idos, era mais facilmente identificável como interesses de uma poderosa minoria. Os Direitos Humanos se distanciaram cada vez mais do conceito de humanidade e do consequente chamado à dignidade. Sua concretização esteve sujeita à definição de quem conta como ser humano a ter seus direitos garantidos: os "humanos direitos"; demonstrando uma gigantesca lacuna entre o Homem abstrato das declarações e os sujeitos de carne, osso e classe social. Se algum discurso sedicioso se propõe a resgatar seu sentido original, relacionado à concepção de cidadania no contexto da Revolução Francesa, é desqualificado junto com o sujeito: defensor de bandido não merece crédito, pois contribui com a violência, sempre atribuída ao outro.

O medo construído a partir de um inimigo suposto (e que, justamente por ser suposto, é inesgotável) e invariavelmente identificado nos setores populares, cumpriu o seu dever: a força policial, hoje, está autorizada a atuar no patamar do massacre.

O Brasil, assim como boa parte do ocidente, optou por uma gestão penal da miséria e da desigualdade. Trata-se, cada vez mais, de fortalecer o Estado Penal para conter o aumento da insegurança objetiva e subjetiva que é, ela mesma, causada pela incapacidade da intervenção estatal para reduzir os desdobramentos da questão social inerente ao capitalismo. Esta alternativa se acirra com algumas particularidades a partir da entrada em cena do neoliberalismo enquanto ideário político e econômico predominante. Nos termos de Wacquant (2003, p. 32), "a mão invisível do mercado encontra seu prolongamento ideológico e seu complemento institucional no 'punho de ferro' do Estado penal", que por sua vez se materializa em práticas de criminalização da pobreza e no refortalecimento das medidas de disciplina e controle direcionadas para aqueles que são as principais vítimas da violência, embora tomados como seus exclusivos algozes: adolescentes e jovens pobres, negros e moradores das periferias urbanas.

A principal proposição de Wacquant nas duas obras em que trata da "nova" governabilidade da miséria $(2001$; 2003) está em demonstrar que a direção punitiva tomada pelas políticas penais nas sociedades ditas avançadas a partir do final do século XX (e copiada em diferentes partes do globo, incluindo o Brasil), consiste na reedição de um governo da insegurança social no sentido de ampliar técnicas e procedimentos destinados a dirigir a conduta daqueles envolvidos na turbulência da desregulamentação econômica neoliberal. No interior dessa proposta de organização, a prisão assume um papel maior que se traduz, para os grupos que vivem nas regiões inferiores da pirâmide social, na imposição de uma tutela severa e minuciosa.

Assim, não nos parece exagero afirmar que a estratégia segregacionista da Política Criminal é parte estruturante da preservação do Capital e revela, no rio de lama de Mariana e no rio de sangue da carne mais barata do mercado, o que significa a Garantia da Lei e da Ordem no acirramento do conflito de classes do Brasil atual.

\section{De qual democracia estamos falando? A adesão subjetiva à barbárie}

Se, para Marx e Engels (1932/2007), é a vida que determina a consciência a partir de suas condições concretas de existência, há de se considerar que a crescente militarização da "questão social" e a execução da política criminal tal qual discutida anteriormente, associada à manipulação ideológica operada, sobretudo, pela mídia empresarial, terá efeitos bastante concretos no cotidiano da população brasileira. Trata-se do entendimento do processo de constituição subjetiva que legitima, reitera e sustenta práticas ditas "democráticas", mas que efetivamente são de segregação e extermínio, alimentadas pelo desejo crescente e massivo por punição.

Caldeira (1991), em uma análise minuciosa da transformação do discurso dos Direitos Humanos em "privilégio de bandidos" no estado de São Paulo, evidencia como a mídia empresarial, via meios de comunicação de massa, inculcou uma relação direta e causal entre a democracia e o aumento da criminalidade. Esse processo se iniciou nos períodos de transição e reabertura democrática na década de 1980, mesma época em que os índices de violência na cidade de São Paulo chegaram a níveis alarmantes e se ensaiava a tentativa de humanização de presídios e de reforma da polícia. Nesse contexto, as notícias destacadas roti-

\footnotetext{
${ }^{2}$ http://brasil.estadao.com.br/noticias/geral,no-brasil-46-aceitam-pena-de-morte-e-51-prisao-perpetua,787757
} 
neiramente pelos programas de rádio, enfatizavam o aumento da criminalidade em função da diminuição do poder de ação da polícia militar após o fim da ditadura, hiperdimensionando episódios de violência, retratados como verdadeiras carnificinas como se fossem a regra do cotidiano das cidades.

Essa estratégia de imposição do medo à população torna-se tão mais sofisticada quanto cruel quando se atualiza nos programas televisivos. Com o recurso da imagem, diversos programas, e especialmente os policialescos, não só narram episódios isolados e grotescos de violência como exploram imagens sanguinolentas, investindo incisivamente em uma via de mão dupla: por um lado, na criação da sensação de que a próxima pessoa a experienciar a violência será o expectador, sempre na condição de vítima; e por outro, na da pessoa exposta ali como criminosa, configurando-a como inimiga, "lixo da humanidade". Ambos investimentos terão consequências desastrosas, sobretudo para as pessoas que são alvo preferencial e histórico da política criminal.

O estereótipo do "bandido" que está nas bordas da humanidade, alheio a sentimentos de compaixão, piedade e que, portanto, executa "crimes cruéis", é endossada constantemente pelos meios de comunicação de massa (Batista, 2012), atualizando uma vez mais as concepções lombrosianas sobre o "homem delinquente": se originalmente esta teoria apregoava que o criminoso traria organicamente, por atavismo ou hereditariedade, a reminiscência de comportamentos adquiridos durante a evolução psicofisiológica (em sua obra são constantemente comparados com "bárbaros" e "selvagens"), possuindo uma tendência inata para o crime e com características especialmente reveladoras de sua delinquência (ânimo violento, espírito vingativo, vaidade instintiva, insensibilidade ou tolerância a dor, ausência do sentimento de compaixão ou indiferença pela desgraça alheia, preguiça e apreço à ociosidade, insensibilidade moral, tendências obscenas ou "forma monstruosa de amor sexual" etc.), hoje esta visão reverbera no próprio conceito de criminalização, entendida como a condenação antecipada de pessoas por questões físicas, sociais, econômicas e/ou geográficas que supostamente revelariam a sua periculosidade.

Usando o medo como metodologia, a mídia propaga um senso comum criminológico que julga feroz- mente pessoas a quem se destina o estigma de "bandidos" ou "vagabundos", incitando e demandando coletivamente o castigo e a punição. Esse julgamento se efetiva com ações cotidianas que se relacionam com o impacto que o discurso midiático tem na vida da população, a exemplo do aumento de episódios de justiçamento nas semanas seguintes à ampla difusão do discurso da jornalista Rachel Sheherazade, em 2014 . Ou ainda se desmembra em um clamor pelo encarceramento em massa, associando segurança pública com o aumento do número de prisões. Não é demais destacar que $57 \%$ da população brasileira concorda com a frase "bandido bom é bandido morto", e que o "país da impunidade" possui a quarta maior população carcerária do mundo; sendo que, ao contrário dos EUA e da Rússia, que ocupam respectivamente, a primeira e a terceira posições - e para os quais há dados mais consolidados -, nossa taxa de encarceramento permanece em ascensão sob o aplauso entusiasmado de amplos setores.

Em paralelo a isso, destaca-se o risco em que se encontram as pessoas "dignas e honestas", bem como suas famílias, consideradas "cidadãos de bem". Essa dualidade foi construída e enfatizada, corroborada por discursos de agentes da segurança pública que afirmavam a ameaça a que estava submetida a população em um momento de mudança social, provocando a sensação de insegurança. Permanecemos, destarte, diante de uma atuação estatal, midiaticamente explorada e socialmente legitimada, que reproduz tradições e valores que rejeitam "visceralmente a noção de direitos universais e divide binariamente os seres humanos em 'cidadãos de bem' (ou 'cidadãos' tout court) e 'não-cidadãos'”. Num gradiente de autoritarismo, sustentado pelo argumento da necessidade de segurança, "essa moral binária (...) oferece suporte à continuidade das práticas policiais ilegais, em nome da pretensa necessidade de se travar uma 'guerra' sem trégua, por todos os meios, contra o crime e a desordem" (Lemgruber, Musumeci, \& Cano, 2003, p. 55).

Ademais, a criação da figura do "cidadão de bem" foi também bastante útil para desarticular a luta em prol dos mínimos direitos para a população prisional. De acordo com Caldeira (1991), a direita se utilizou da equiparação entre direitos civis individuais à noção de privilégios, investindo no argumento de que se queria transformar prisões em hotéis luxuosos e dar

${ }^{3}$ Sistema Brasileiro de Televisão (SBT) (Produtor). (2014). Telejornal SBT Brasil - 4 de fevereiro de 2014 - $1^{\circ}$ bloco. [Vídeo]. Recuperado de https://www.youtube.com/watch?v=yxSr0ht8vgM 
boa vida aos "bandidos", que zombariam das pessoas que lutam para sobreviver "de forma honesta". Tais elementos contribuíram para equiparar a luta pelos direitos à "privilégio de bandido", quando a realidade do sistema prisional brasileiro é assustadoramente oposta a qualquer privilégio.

No campo psi, Martín-Baró (1990), em Psicología social de la guerra, apontava para as características psicossociais de contextos de conflitos declarados, ao analisar a condição de El Salvador. Nesse sentido, podemos articular tais apontamentos com as questões aqui apresentadas ao analisar as permanências da ditadura nas políticas de segurança e sua disseminação no corpo social a partir dos elementos tratados por Baró, tais como: processos de militarização da vida cotidiana e "das mentes", a veiculação de mentiras institucionalizadas a partir das expressões midiáticas da ideologia dominante, e a cristalização das relações sociais, redundando numa polarização social, a qual determina quais são os sujeitos que devem ser encarcerados, exterminados, aniquilados da sociedade.

Desse modo, os estereótipos forjados sob medida para legitimar a execução da política criminal no Estado Democrático de Direito, associados aos discursos contra os direitos humanos, escamoteiam os interesses de classe aí contidos: a manutenção dos privilégios da elite brasileira. Em um contexto nacional de expansão dos direitos, a partir da conquista das lutas populares e dos movimentos sociais na década de 1980, o crime se torna justamente um meio de articular discursos contra os direitos, sobretudo, de pessoas empobrecidas, amparado na noção de periculosidade e propensão para o crime, herdada das teorias e práticas higienistas e eugênicas.

A semelhança com outros períodos de nossa história não é mera coincidência. No contexto de consolidação da República, no final do século XIX e início do século $\mathrm{XX}$, a valoração positiva do trabalho após séculos de regime escravagista ganha contornos particulares na conjuntura nacional, articulado aos ideários positivista, de "ordem" e "progresso", e à eugenia, articulada ao conceito de degenerescência. O que estava em jogo, portanto, não era "somente" a construção de um novo regime político e econômico, mas igualmente a conservação e justificação de uma hierarquia social arraigada. Assim, tem início o regime republicano, em meio às grandes transformações políticas, econômicas e sociais geradas, dentre outros fatores, pela abolição do regime escravocrata e pela ação dos médicos higie- nistas. Ao mesmo tempo em que se verifica a expansão populacional em centros urbanos e o desenvolvimento do comércio e da indústria, surge um novo projeto de Nação especialmente empenhado em fortalecer o Estado e moralizar as famílias, sobretudo através da imposição do trabalho assalariado.

\section{A Psicologia que não teme tomar partido: provocações necessárias}

Após 55 anos da promulgação da Lei n ${ }^{\circ}$ 4.119/1962 (Brasil, 1962), que regulamenta a profissão da Psicologia no Brasil, muitos foram os desdobramentos de nossa ciência e profissão que merecem destaques ao analisarmos o contexto político-social brasileiro e as convocações históricas a que a Psicologia buscou responder nesse período. Constituída como uma profissão que tem como função privativa a utilização de métodos e técnicas psicológicas com objetivos de diagnóstico psicológico, de orientação e seleção profissional, de orientação psicopedagógica e de solução de problemas de ajustamento, conforme descrito no texto legal, a história de nossa profissão expressa também as conflitivas sociais determinantes na relação com as demandas frente às desigualdades vividas pela maioria da população brasileira.

Nesse contexto, discorrer sobre o compromisso ético-político de nossa profissão, em verdade, significa analisar as contradições postas no desenvolvimento do Estado Brasileiro, buscando compreender a Psicologia como um conjunto de contribuições sociotécnicas inseridas na totalidade das relações sociais, e que tem, desde o seu surgimento, produzido respostas e posicionamentos diante das demandas que lhe são apresentadas. Tais contribuições denotam determinados compromissos e objetivos, os quais são fundamentais para compreendermos o movimento constante de construção de suas teorias e práticas.

Deforma hegemônica, a Psicologia desenvolveu-se pautada na construção de técnicas e métodos, por meio das bases teóricas, mormente importadas de outros países e oriundas de outros contextos sociais, com o intuito primordial de fazer valer a promoção de "ajustamentos de conduta". Foi assim nas escolas, nas fábricas e empresas, nas instituições assistenciais, na relação com a justiça e, ainda mais enfaticamente, nos espaços privados das clínicas psicológicas.

A legitimação de constructo teórico expresso pelos contornos de uma individualidade destacada das relações sociais é condição fundamental para o desenvol- 
vimento de processos de controle, disciplina e pretenso apaziguamento dos sujeitos frente aos conflitos sociais vivenciados, escamoteando-se, assim, a processualidade e o movimento dialético da constituição de individualidade. A validação de traços de personalidade, a predominância do foco na doença, esta fundamentalmente de responsabilidade de cada sujeito, a elaboração de crivos para marcadores sociais de diferença, traduzidos em características individuais naturais, e a produção teórica sobre o que deve ser considerado normal, foram constituindo a prática dominante da Psicologia desde seu surgimento. Nossa ciência e profissão foi peça importante, nesses termos, para a instauração e manutenção do capitalismo e isto deve ser posto em análise, sob pena de reproduzirmos discursos meramente alegóricos sobre nosso papel.

Como Martín-Baró (1997) já nos ensinou, a Psicologia ainda tem permanecido numa relação servil em relação aos interesses dominantes, bem como à apropriação colonizada de teorizações, no levantamento de questões e de produção de respostas, como distante e alheia aos anseios sociais dos povos latino-americanos. Um dos vieses colonizadores tem sido a tendência ao "psicologismo" como gabarito para a compreensão de complexos problemas sociais encarnados dialética e contraditoriamente nas histórias de vidas de sujeitos singulares.

Löwy (1994), inspirado por Rosa Luxemburgo, apresenta a metáfora do mirante para nos dizer que há uma relação intrínseca entre a posição social do pesquisador (e podemos dizer de todo profissional) e seu horizonte de visibilidade do movimento do real, a qual se desdobra na definição de um "ponto de vista" que não tem interesse em escamotear a realidade (produzindo e reproduzindo a mistificação) e que dá condições de se vislumbrar as múltiplas determinações do objeto a ser estudado (e a realidade da intervenção). A visão de mundo e concepção de ser humano do pesquisador - e porque não, da(o) psicó$\operatorname{loga}(0)$ ? -, portanto, são elementos que precisam ser explicitados nesse processo de produção de conhecimento e não são estranhas ao estatuto da ciência ou da práxis profissional. Dessa forma, cabe-nos indagar: sob qual mirante nos assentamos para conhecer aqueles que atendemos e para desenvolver e realizar as práticas psicológicas?

Como já pontuado anteriormente, a história da América Latina é recheada de episódios de violência, de dominação e opressão, histórias de invasão e colonização, de extermínio de seus povos originários, de escravização, de desigualdades sociais, guerras civis, militarismo e ditaduras civis-militares financiadas pelo imperialismo estadunidense como tática para a expansão do capitalismo entre os países subdesenvolvidos. Muito recentemente, esta história está pautada por um frágil processo de uma "abertura democrática” em vários de seus países, baseado em uma débil emancipação política como corolário de uma pretensa conquista de cidadania burguesa. Conflitos agrários, precarização do trabalho, baixo índice de desenvolvimento humano (IDH), desintegração de recursos naturais, ações policialescas e políticas neoliberais dão o tom de muitas das contradições atuais que ainda vivenciamos em nosso território latino-americano. A partir do desenvolvimento do trabalho assim chamado livre no território brasileiro, temos que necessariamente discutir as dimensões e contradições no mundo do trabalho, além do determinante fundante de classe social, também a partir também dos recortes raciais e de gênero. Nesse sentido, cabe-nos destacar que o racismo e o machismo incidem sobre a precarização do trabalho, pois há o desenvolvimento de justificativas ideológicas para a mão de obra negra e feminina ser superexplorada a partir do desenvolvimento do capitalismo.

Dessa forma, para analisarmos a relação do desenvolvimento da Psicologia como ciência e profissão e o da história do Brasil, nessa perspectiva, há que se rechaçar, portanto, as concepções que visam à harmonização da formação social brasileira, escamoteando as raízes da violência trans-históricas pautadas pelo racismo e pelo patriarcalismo que fundaram a ideia de "Brasil Moderno".

Resgatamos aqui o sentido do compromisso ético-político de nossa profissão, calcado na radicalidade da compreensão dos determinantes histórico-sociais a que estão submetidos os povos latino-americanos, a partir da especificidade de como isso se desdobra em nosso país. Há que se partir das vozes das resistências, dos enfrentamentos e das transformações realizadas no interior de nossa prática profissional em diálogo com os coletivos e grupos atendidos em sua história de lutas, confrontos e insurgências. Cabe-nos falar, nesse contexto, partir de uma Psicologia que se pretende indisciplinada, por não se pautar pela disciplinarização dos sujeitos, e de libertação/emancipação humana para produzirmos formas de cuidado e de intervenção voltada à nossa população. 


\section{Considerações finais}

A história não é linear e nem se desenvolve necessariamente no sentido do progresso emancipatório da humanidade. As diferentes concepções se interpenetram e se atualizam, as múltiplas e contraditórias determinações concretas dos modos de produzir e reproduzir a vida se inter-relacionam. À inferioridade jurídica e biológica, inicialmente atestada "cientificamente", soma-se à social. Sua desconstrução, na teoria, não se desdobrou numa desconstrução prática.

O estereotipo do delinquente, ainda hoje sintomaticamente chamado "vagabundo", ganha novos ares: um jovem negro, morador da favela, próximo ao tráfico de drogas, de boné, cordões e "portador de algum sinal de orgulho ou de poder e nenhum sinal de resignação ao desolador cenário de miséria e fome que o circunda" (Zaccone, 2013, p. 21). Este sujeito/objeto forjado pela teoria criminológica só pode ser compreendido se atentarmos para a demanda por ordem em cada momento histórico.

As contradições sociais necessitam ser administradas, de uma forma ou de outra, pelo Estado burguês. No caso dos setores mais precarizados, sua ação tem forte viés punitivo e coercitivo, sentido com particular violência por crianças e jovens. Tal realidade impõe, àqueles que possuem algum compromisso com os direitos humanos, a tarefa de uma crítica radical ao modelo criminalizante.

Nesse sentido, talvez a primeira e mais difícil tarefa seja abandonar a ideia de que direitos são sinônimo de justiça e, sobretudo, abandonar a fé no poder punitivo para a resolução de conflitos. Isso significa repensar o modo como temos abordado opressões históricas, uma vez que a crítica, mesmo quando acertada, não tem contribuído em ações para a resolução ou superação da realidade posta, muitas vezes, inclusive, utilizando-se de argumentos que reverberam na ampliação da criminalização e do encarceramento.

O problema comum da criminologia tradicional está na necessidade de ordem numa perspectiva de luta de classes. É essa ligação com o fio condutor da história - a luta de classes - que não podemos perder de vista. Como afirma Batista (2012, p. 22), "ela nunca foi tão visível e palpável como na dura conflitividade social do dia a dia do capitalismo de barbárie: garotos morrendo ou matando por um boné de marca". Qualquer proposta que vislumbre a redução da letalidade do sistema penal em nosso país deve incluir, portanto, a contenção do poder punitivo. E à Psicologia está posto o desafio de revisitar-se, com vistas a ampliar suas contribuições possíveis nessa empreitada.

\section{Referências}

Agamben, G. (2014, 6 de dezembro). Como a obsessão por segurança muda a democracia. In Le Monde Diplomatique Brasil. Recuperado de http://www.diplomatique.org.br/artigo.php?id=1568

Agamben, G. (2004). Estado de sítio. São Paulo, SP: Boitempo.

Baratta, A. (2002). Criminologia crítica e crítica do Direito Penal: introdução à sociologia do direito penal. Rio de Janeiro, RJ: Revan.

Batista, N. (2011). Introdução crítica ao direito penal brasileiro. Rio de Janeiro, RJ: Revan.

Batista, N. (1990). Punidos e mal pagos: violência, justiça, segurança pública e direitos humanos no Brasil de hoje. Rio de Janeiro, RJ: Revan.

Batista, V. M. (2012). Introdução crítica à criminologia brasileira. Rio de Janeiro, RJ: Revan.

Beccaria, C. (2006). Dos delitos e das penas. São Paulo, SP: Ícone. (Texto original publicado em 1764).

Bobbio, N. (1998). Diário de um século: autobiografia. Rio de Janeiro: Campus.

Brasil (1962, 5 de setembro). Lei No 4.119, de 27 de agosto de 1962. Dispõe sobre os cursos de formação em psicologia e regulamenta a profissão de psicólogo. Diário Oficial da União.

Caldeira, T. (1991). Direitos humanos ou "privilégio de bandidos"? Desventuras da democratização brasileira. Novos Estudos, (30), 162-174.

Castro, L. A. (2005). Criminologia da libertação. Rio de Janeiro, RJ: Revan.

Cerqueira, C. (1998). Questões preliminares para a discussão de uma proposta de diretrizes constitucionais sobre segurança pública. Revista Brasileira de Ciências Criminais, 6(22), 139-182. 
Douzinas, C. (2011). Os paradoxos dos direitos humanos. In Anuário do Núcleo Interdisciplinar de Estudos e Pesquisas em Direitos Humanos/UFG (pp. 1-15). Recuperado de https://www.cienciassociais.ufg.br/up/106/o/ConferenciaAberturax.pdf?1350490879

Foucault, M. (1987). Vigiar e punir: nascimento da prisão. Petrópolis, RJ: Vozes.

Galeano, E. (2013). De pernas pro ar: a escola do mundo ao avesso (S. Faraco, Trad.). Porto Alegre: L\&PM. (Texto original publicado em 1940).

Lane, S. T. M. (1984). A psicologia social e uma nova concepção de homem para a Psicologia. In S. T. M. Lane, \&W. Codo (Eds.), Psicologia social: o homem em movimento (pp. 10-19). São Paulo, SP: Brasiliense.

Lemgruber, J., Musumeci, L., \& Cano, I. (2003). Quem vigia os vigias? Um estudo sobre controle externo da polícia no Brasil. Rio de Janeiro, RJ: Record.

Löwy, M. (1994). As aventuras de Karl Marx contra o Barão de Münchhausen: marxismo e positivismo na sociologia do conhecimento. São Paulo, SP: Cortez.

Löwy, M. (2005). Walter Benjamin: aviso de incêndio: uma leitura das teses "Sobre o Conceito de História". São Paulo, SP: Boitempo.

Martín-Baró, I. (1990). Psicología social de la guerra: trauma y terapia. San Salvador: UCA Editores.

Martín-Baró, I. (1997). O papel do Psicólogo. Estudos de Psicologia (Natal), 2(1), 7-27. https://doi.org/10.1590/ S1413-294X1997000100002

Martins, J. S. (1997). Exclusão social e a nova desigualdade. São Paulo, SP: Paulus.

Marx, K., \& Engels, F. (2007). A ideologia alemã. São Paulo, SP: Boitempo. (Texto original publicado em 1932).

Melossi, D., \& Pavarini, M. (2006). Cárcere e fábrica: as origens do sistema penitenciário. Rio de Janeiro, RJ: Revan.

Netto, J. P. (2001). Cinco notas a propósito da questão social. Revista Temporalis, 2(3), 41-49.

Netto, J. P. (2012). Crise do capital e consequências societárias. Serviço Social \& Sociedade, (111), 413-429. https:// doi.org/10.1590/S0101-66282012000300002

Ribeiro, D. (1995). O povo brasileiro: a formação e o sentido do Brasil. São Paulo, SP: Companhia das Letras.

Rolim, M. (2006). A síndrome da rainha vermelha: policiamento e segurança pública no século XXI. Rio de Janeiro, RJ: Jorge Zahar.

Rusche, G., \& Kirchheimer, O. (2004). Punição e estrutura social. Rio de Janeiro, RJ: Revan.

Wacquant, L. (2001). As prisões da miséria. Rio de Janeiro, RJ: Jorge Zahar.

Wacquant, L. (2003). Punir os Pobres: a nova gestão da miséria nos Estados Unidos. Rio de Janeiro, RJ: Freitas Bastos.

Zaccone, O. (2013). Indignos de vida: a forma jurídica da política de extermínio de inimigos na cidade do rio de janeiro. Tese de Doutorado, Universidade Federal Fluminense, Niterói, RJ.

Zaffaroni, E. R. (2007). O inimigo no direito penal. Rio de Janeiro: Revan.

Zaverucha, J. (2010). Relações civil-militares: o legado autoritário da constituição brasileira de 1988. In E. Teles, \&V. Safatle (Orgs.), O que resta da ditadura: a exceção brasileira (pp. 41-76). São Paulo, SP: Boitempo.

\section{Ana Vládia Holanda Cruz}

Doutora e Mestre em Psicologia pela Universidade Federal do Rio Grande do Norte (UFRN), Natal - RN. Brasil. Professora da Faculdade DeVry Fanor, Fortaleza - CE. Brasil.

E-mail: anavladiahc@gmail.com 


\section{Tatiana Minchoni}

Mestre em Psicologia pela Universidade Federal do Rio Grande do Norte (UFRN), Natal - RN. Brasil. Doutoranda do Programa de Pós-Graduação em Psicologia da Universidade Federal de Santa Catarina (UFSC), Florianópolis - SC. Bolsista do Conselho Nacional de Desenvolvimento Científico e Tecnológico (CNPq). Brasil.

E-mail: minchoni.tatiana@gmail.com

\section{Adriana Eiko Matsumoto}

Doutora em Psicologia Social pela Pontifícia Universidade Católica de São Paulo (PUC-SP), São Paulo - SP. Brasil. Professora da Universidade Federal Fluminense (UFF), Volta Redonda - RJ. Brasil.

E-mail: drieiko@hotmail.com

\section{Soraya Souza de Andrade}

Doutora em Ciências do Desenvolvimento Socioambiental pela Universidade Federal do Pará (UFPA), Belém, PA. Brasil. E-mail: soraya.souzandrade@gmail.com

Endereço para envio de correspondência:

Soraya Souza de Andrade

QI 20, conjunto B, casa 114, Guará I. CEP: 71015-026.

Brasília - DF. Brasil.

Recebido 30/06/2017

Reformulação 15/09/2017

Aprovado 25/09/2017

Received 06/30/2017

Reformulated $09 / 15 / 2017$

Approved 09/25/2017

Recebido 30/06/2017

Reformulado 15/09/2017

Aceptado 25/09/2017

Como citar: Cruz, A. V. H., Minchoni, T., Matsumoto, A. E., \& Andrade, S. S. (2017 ). A ditadura que se perpetua: direitos humanos e a militarização da questão social. Psicologia: Ciência e Profissão, 37(n. spe), 239-252. https://doi.org/10.1590/1982-3703180002017

How to cite: Cruz, A. V. H., Minchoni, T., Matsumoto, A. E., \& Andrade, S. S. (2017). The dictatorship that remains: human rights and the militarization of the social issue. Psicologia: Ciência e Profissão, 37(n. spe), 239-252. https://doi.org/10.1590/1982-3703180002017

Cómo citar: Cruz, A. V. H., Minchoni, T., Matsumoto, A. E., \& Andrade, S. S. (2017). La dictadura que se perpetúa: derechos humanos y la militarización de la cuestión social. Psicologia: Ciência e Profissão, 37(n. spe), 239-252. https://doi.org/10.1590/1982-3703180002017 